\title{
EU Agricultural Digitalization Decalogue
}

\author{
N. B. Kondratieva ${ }^{\#}$ \\ Institute of Europe, Russian Academy of Sciences, Moscow, 125009 Russia \\ e-mail: nkondratieva@inbox.ru
}

Received November 25, 2020; revised November 25, 2020; accepted November 25, 2020

\begin{abstract}
The aim of the article is to summarize the ideological foundations and to characterize the current stage of agricultural digitalization in the EU. The author identifies the framework documents and areas of discussion on the development of the digital strategy of the European Union in the agricultural sector. Taking into account the successful practice and opinions of the competent centers, an idea was formed about the principles and ten areas that are covered by supranational assistance, which form a kind of Decalogue of agricultural digitalization. The author notes that the regulation of digital transformation in agriculture is due not so much to the need to increase the economic efficiency of business processes, but rather to the intention to facilitate the control of their compliance with the criteria of climate neutrality and inclusiveness. The digitalization strategy of the Common agricultural policy (CAP) brings its goals closer to those of sustainable development. The ongoing crisis in Europe and the world caused by the COVID-19 coronavirus pandemic gives the European Commission a formal reason to step up digital transformation in agriculture. Relying on legal and investment-based regulatory tools, it uses tactics to force progress in the name of improving the sustainability of agriculture in the face of probable shocks.
\end{abstract}

Keywords: digital strategy, common agricultural policy, supranational regulation, COVID-19 pandemic, sustainable development, global climate change.

DOI: $10.1134 / \mathrm{S} 1019331621060150$

Global climate change and the development of digital technologies are the key factors which today determine the supranational intervention in the agricultural economy of the EU. Even though both of them create an existential risk for the European agriculture they also encourage competition in the agricultural market and the industry's progress. Unlike climate change, digital transformation is already manageable; the latter is viewed by supranational institutions as a tool to control the former.

The COVID-19 pandemic demonstrated the importance of digital skills for working in the conditions of restrictions on the movement of people and it gave momentum to transformations and to the inclusion of digital priorities in the sectoral activities of the EU. In particular, the pandemic highlighted the risks of disrupting seasonal work in agriculture [1] and, at the same time, it strengthened the society's agreement with the remote work mode and revealed the need for digitalization in many areas of rural life.

For example, a special analytical note by the OECD [2], published in June 2020 and dedicated to the consequences of the pandemic for rural development offers a new vision of rural areas as a safer place

\footnotetext{
\# Nataliya Borisovna Kondrat'eva, Cand. Sci. (Econ.), is an Associate Professor and Learned Secretary at the RAS Institute of Europe.
}

of residence, which has become a temporary refuge for urban dwellers. The document noted not only a shortage of medical institutions and cultural facilities, but also underdevelopment in the availability of water, electricity and gas supply, sewer and wired telecommunication systems, which certainly hindered the ability of rural areas to replace urban environment. However, in those rural areas where the level of digital infrastructure was sufficient, it made up for the lack of other amenities.

The crisis that prompted the public discussion is accelerating the achievement of consensus on framework, legislative and investment initiatives in the field of agrarian digitalization; The European Commission (EC) is effectively getting carte blanche for a sustainable digital agenda.

This study examines the problems of digital transformation in agriculture. In the first part its ideological foundations and its challenges are identified, in the second part the progress of appropriate reforms within the EU's competence is traced. The author aims to record the fact of the creation of sustainable digital agriculture as a priority issue of the EU's Common Agricultural Policy under the influence of the respective academic field. The research methods used to achieve the goal include the analysis of official reports, 
the study of strategic attitudes and the search for practical examples of activities.

\section{METHODOLOGY}

The analysis is based on the concept of sustainable development and the new institutional economic theory. Being developed since the 1970s, they have been thoroughly researched and provide guidance in specific practical areas. Nowadays the concept of sustainable development offers a basis for radical transformations in the economy which minimize environmental damage (though often at a high cost) and which in the long term will demonstrate their economic efficiency [3-5].

One of the research fields within this concept is "green economy" which focuses on increasing the role of renewable energy sources and environmentally friendly technologies in the economic development and predicts the depreciation of assets of the owners of hydrocarbon resources [6,7]. In the past decade another research field has been growing with the same dynamics-the "digital economy" which studies the processes of the creation and the dissemination of digital technologies [8, 27]. In a number of works the role of digital technologies in the proliferation of green technologies is substantiated. Moreover, green and digital economies are seen together as a driving force and a sign of the countries' transition to a new technological order. The concept of "sustainable digital economy" is proposed, which develops the idea of a synergistic effect of connecting two economies [911]. A separate category includes works that study its challenges [12]. Such studies serve as a rationale for the need to regulate and encourage a sustainable digital economy [13]. The works within the framework of the new institutional economic theory help to evaluate the approach used by the supranational institutions of the EU for the implementation of the strategic guidelines [14-16].

The research literature offers a view that the benefits of digitalization should be measured beyond the traditional indicators of trade growth and economic efficiency. An important criterion is public welfare. It is this emphasis that inspires the EU's Digital Strategy.

Let us elaborate on that. The digital economy does not live up to expectations: instead of increasing profits by reducing costs of manual labour, funds, communications, transport, it increases expenses for the payment of qualified personnel, purchase of technology and equipment. Back in the late 1980s, American economist R. Solow, a Nobel laureate wrote: "You can see the computer age everywhere but in the productivity statistics." ${ }^{1}$ A leading Russian economist S. Afontsev noted the reduction in the contribution of world trade to GDP (at the height of its digitalization, N.K.'s

\footnotetext{
${ }^{1}$ Robert Solow, "We'd better watch out", New York Times Book Review, July 12 (1987), p. 36.
}

note) [17]. The paradoxes of digitalization force us to reformulate its assessment.

As criteria, it makes sense to propose the value contribution of the digital economy to public welfare. If the use of digital technologies helps to meet environmental standards, develop professional skills, protect the rights of workers and consumers, and create an accessible environment, then the development of political and legal methods of forcing economic actors to bear the necessary costs is justified. The inclusion of such expenses in state budgets is also justified. The leading British environmental economist T. Jackson wrote about it: "Simplistic assumptions that capitalism's propensity for efficiency will allow us to stabilise the climate and protect against resource scarcity are nothing short of delusional" [18, p. 8] (without the intervention of supranational institutions and international organizations, note N.K.); an American Nobel laureate J. Stiglitz emphasized that "only a new social contract-guaranteeing citizens health care, education, retirement security, affordable housing, and decent work for decent pay-can save capitalism and liberal democracy" [19]. As for the EU, the current stage in its development is characterized by an increase in costs which cannot be avoided since consensus was reached on them as a result of broad public discussion and they have already become part of the social contract. The European model of a coordinated market, where Schumpeterian "effective" competition is in action, allows for a subsidiary support of market actors by supranational institutions; this regulation is operationalized by the inclusion of quantitative benchmarks that strengthen the foundation of European values in various areas (social development, ecology, and now also digitalization).

In the research of this topic we can identify two groups of studies. The first group provides insight into the risks of digital transformation of agriculture. The second group of papers examines the role of digital technologies in the implementation of the Strategy for Smart, Sustainable and Inclusive Growth and the new EC Green Deal. Both have a common element-recommendations to encourage digitalization.

Within the first approach we can mention a number of FAO and EC reports [20, 21]. They suggest a relatively low starting level of indicators of rural areas for the purposes of digital economy, which can result in an uneven territorial distribution of its benefits and an even greater gap between rural areas and urban areas. Thus, the indicators of labour productivity in rural areas of the EU are $80 \%$ of the level of urban areas, income and wages $-60 \% .31 \%$ of all farmers in the EU are over 65 (in Portugal, in particular, half of them), while only $6 \%$ of farmers are under 35 . Thus, for one farmer under 35 , there are 6 farmers over $65.70 \%$ of farmers have received no agricultural training other than their own practical experience. In Romania, Bulgaria, Greece, Croatia, Cyprus, and Malta, this share 
exceeds 90\%. [22, pp. 8, 9]). The reports, however, formulate the idea of the vast possibilities of digital technologies to increase the inclusion of rural areas into market relations.

Within the framework of the second approach one can identify the works studying the evolution of the CAP EEC/EU [23-25] starting in 1965 and up to the stage of digitalization (smart farming) as a policy for managing the data on prices, volumes and conditions of agricultural production. The experts substantiated the opportunity to direct wireless technologies, Internet of things, artificial intelligence and blockchain to the service of such EU priorities as environmental protection, innovation and inclusiveness.

The analysis of a vast number of sources and research literature allows us to identify ten areas of supranational regulation of agrarian digitalization. Successful examples are proof of its broad prospects. With each of these directions being justified by a socially significant goal they turn into a kind of decalogue: ${ }^{2}$

-Adequate telecommunication connection. The goal is giving access to the market and resources for more economic actors.

-Combining artificial intelligence technologies with traditional geological information systems. The goal is to rationalize land use, increase yields and reduce operating costs. An example of this is GAIA ${ }^{3}-$ a web-based application for manufacturers, regulators and biosecurity organizations. It helps to analyse highresolution satellite images and aerial photographs, including those taken by unmanned aerial vehicles. It automatically identifies and analyses plantings of valuable crops, determines the area of crops, their condition, suggests a rational arrangement of plantings on slopes, etc. This application was used to conduct the National Vineyard Censuses in Europe and Australia, which made it possible to represent the state of development of their own industry and those of competitors with more accuracy (in comparison with the timeconsuming and expensive manual data collection).

-Implementation of platform recycling technologies. The goal is the optimal distribution of residues and surpluses, reduction of food waste, support of vulnerable segments of the population. An example of this technology in use is chain retail stores. For example, in 2016 Ahold Delhaize was one of the first in the EU to introduce digital technology for discounting expiring products in order to reduce losses, waste and to increase the number of consumers.

\footnotetext{
${ }^{2}$ Structuring a problem with the designation of 10-12 approaches to its solution as the basis for setting goals, developing rules or learning lessons is a favourite method of the Center for European Policy Studies (Think tank of the official Brussels, CEPS).

3 Project GAIA (2019). https://projectgaia.ai/. Cited November 10, 2020.
}

-Prohibition of discrimination in electronic commerce; inclusion of sustainable development criteria and evidence-based utility criteria in the online advertising of agricultural products. The goal is to strengthen the foundations of the EU's unified agricultural market.

- The use of blockchain technologies in the supply of agricultural products. The goal is to increase market transparency. Since 2017 the food giants Walmart, Nestlé and Unilever have been using blockchain in partnership with technology companies FreshSurety, AgriDigital, HarvestMark, FoodLogiQ, and Ripe.io.

-Application of interactive models of providing consulting services, transferring basic skills, strengthening the foundations of partnerships. The goal is to create favourable environment for the early introduction of R\&D into practice; adaptation and achievement of the equality of opportunities for all categories of farmers; balanced territorial development. One of the examples is the startup WeFarm (London) which is positioned by analysts as the world's largest knowledge exchange network for small farmers. In the years 2014-2020 The European Innovation Partnership for Agricultural Productivity and Sustainability (EIP-AGRI) was funded by the EU budget through the European Agricultural Fund for Rural Development and the Horizon 2020 program. In the future the EC intends to expand this project by creating the so-called interactive systems for the dissemination of agricultural knowledge and innovation (Agricultural Knowledge and Innovation Systems, AKIS $)^{4}$ with the participation of agricultural actors from various member states.

- Using the Internet of Things to collect agricultural data. The goal is to obtain objective data and monitor problems. An example of this are devices incorporated into harvesting machines that map acreage, collect yield data, data of seed, fertilizer or pesticide application and help prove that the crop was grown under the right conditions.

- Providing incentives for the accumulation and dissemination of the data that belong to the farmer. The goal is to strengthen the foundations of the data economy.

- Responsibility for non-compliance with rules and targets. The goal is effective competition and decrease in market concentration. New regulations adopted by the European Commission and effective in 2018 allow Copernicus and Sentinel satellites and other Earth observation data to be used as primary evidence $^{5}$ in verifying the farmers' compliance with the European environmental, animal welfare standards and other requirements before calculating payments

\footnotetext{
${ }^{4}$ Building stronger agricultural knowledge and innovation systems (AKIS) to foster advice, knowledge, and innovation in agriculture and rural areas. European Commission. April 2019.

${ }^{5}$ For details see [28].
} 
from the European Agrarian Fund. Several commercial platforms which provide the necessary services to farmers are already operating according to these rules-RECAP, APII, NIVA, etc.

-Application of ethical standards in data management and the development of artificial intelligence. The goal is strengthening the foundations of sustainable development, observing security and privacy. In the end of 2018 the institutes reached an agreement on a European cybersecurity certification for digital products/services and on a permanent mandate for the EU Cybersecurity Agency ENISA to issue such certificates. The basis for the development of Euro standards is formulated in the 2020 White Paper on

Artificial Intelligence. ${ }^{6}$ It lists the circumstances that justify the use of such technologies in public space and also gives an idea of assessing the compliance of artificial intelligence systems with safety requirements according to four criteria-compliance with European values and rules; clear information, understandable for an ordinary user, about the purpose of the proposed technology, its capabilities and limits; technical reliability and accuracy; the existence of an adequate level of human control of the system.

\section{DIGITAL AGENDA OF THE CAP}

In comparison with the documents on the arrangement of the EU digital single market that were issued five years ago the digital strategy for the next decade has a broader outline. Specifically, it makes digital technologies subordinate to the solution of the comprehensive task of sustainable and balanced growth. In February 2020 the basic document was released-the message on "Shaping Europe's Digital Future"7 and two reference documents - the aforementioned White Paper on Artificial Intelligence and the European Data Strategy ${ }^{8}$ in March-Small and Medium Enterprises strategy ${ }^{9}$ as the third reference document.

Agriculture is viewed as one of the areas of application of the new digital strategy. The EC documents emphasize the responsibility of the industry for a significant part of greenhouse gas emissions and chemical pollution, for the use of water resources, a decrease in biodiversity and the overproduction of food leading to additional waste and unhealthy consumption. Since agriculture is a traditional area of concern for EU institutions, it is accepted as a space in which bold actions can be taken, specifically-requiring compli-

\footnotetext{
${ }^{6}$ White Paper on Artificial Intelligence-A European approach to excellence and trust, COM(2020) 65 final.

${ }^{7}$ Shaping Europe's digital future, COM (2020) 67 final.

${ }^{8}$ A European strategy for data, COM (2020) 66 final.

${ }^{9}$ An SME Strategy for a sustainable and digital Europe, $\operatorname{COM}(2020) 103$ final.
}

ance with the European security standards for digital data ordering and artificial intelligence.

In 2018 digital priorities formed the basis in the legislative proposal for the next reform of the Common Agricultural Policy. Respectively, agriculture has been identified as one of the key application areas for European investment in the EC's Plan for the Development of Artificial Intelligence Technologies. ${ }^{10}$ In 2019 agricultural reform was included in the new Green Deal. ${ }^{11}$

The key document was published in early 2020. It is the European Commission's Strategy for Strengthening Biodiversity and Implementation of Sustainable Development Indicators in Agriculture, entitled "From Farm to Fork." 12 The document contains quantitative guidelines for the creation of an ecologically clean agricultural and food system of a closed type in the European Union. The Strategy is based, firstly, on a draft climate law ${ }^{13}$ setting the goal of creating a climate-neutral Union in 2050, the fate of which will be decided by the December EU summit; secondly, the September 2020 climate target plan until 2030 , where the goal is to further reduce greenhouse gas emissions to $55 \%$ compared to 1990 levels. Thirdly, by 2030 the goal is set to reduce the use of pesticides by $50 \%$, fertilizers-by $20 \%$, antimicrobial drugs used for farm animals and aquaculture-by $50 \%$, thus bringing the share of agricultural land under organic farming to $25 \%$. The document contains other indicators that need to be corrected, for example, the number of 33 million residents of the European Union who do not receive a balanced diet every second day, and, conversely, $20 \%$ of the products of the EU food industry which are thrown away since no consumer was found for it. In the preamble it is noted that the COVID-19 pandemic is further encouraging Europeans to create a reliable and sustainable food system that will function under all circumstances. This document sets the goal of the Common Agricultural Policy for the next seven years: the creation of a technological, open (based on the exchange of data), inclusive, waste-free and clean (in terms of protecting the environment and human health) agriculture. As follows from the document, digital technologies and communications are becoming a key factor in this policy, combining agricultural R\&D with the process of collecting data, mastering knowledge and achieving tar-

\footnotetext{
${ }^{10}$ Communication on Artificial Intelligence for Europe, COM(2018) 237 final, The EU Coordinated Plan on Artificial Intelligence COM(2018) 795 final.

${ }^{11}$ The European Green Deal. COM/2019/640 final.

${ }^{12}$ Farm to Fork Strategy. For a fair, healthy and environmentallyfriendly food system. European Union, 2020.

${ }^{13}$ Commission proposal for a Regulation of the European Parliament and of the Council establishing the framework for achieving climate neutrality and amending Regulation (EU) 2018/1999 (European Climate Law), COM(2020) 80 final, 2020/0036 (COD).
} 
gets. The improvement in Internet communications, the introduction of artificial intelligence and other digital solutions are the basis for the transition to precision farming, objective data analysis, reducing agricultural overproduction, improving soil and water management, rational use of fertilizers and antimicrobial drugs, reducing greenhouse gas emissions and the use of pesticides and ensuring a closed production cycle.

The EC's response to the deepening of the coronavirus crisis was expressed in its setting the goal to eliminate the shortage of digital assets and accelerate the accumulation of data, as well as to achieve a balance in the development of two areas of the Common Agricultural Policy-support for agricultural workers and for the rural areas as such. Since March 2020, the EC's special authorized body for the regulation of electronic communications (The Body of European Regulators of Electronic Communications, BEREC) has been monitoring problems with Internet traffic in each member state and also accumulating examples of possible solutions in the field of artificial intelligence and robotics. The stage of the dissemination of successful practices is still ahead. But as early as in 2021 we should expect the acceleration of the process of replacing physical labour with machine labour in agriculture. ${ }^{14}$

\section{THE STRATEGY OF PROGRESS ENFORCEMENT}

Initial information on the dynamics of digitalization in agriculture and rural areas of the EU can be borrowed from the annually published comprehensive Digital Economy and Society Index (DESI; the last reporting document was released in June 2020 but it was compiled using the 2019 data, that is, even before the pandemic). It is important to note that in terms of $4 \mathrm{G}$ coverage, the gap in rural areas has been almost completely overcome; this type of communication is available on $99.4 \%$ of the EU territory. However, the Internet of Things (digital devices embedded in agricultural machinery) requires reliance on the next generation of mobile technologies. Higher bandwidth networks (5G) are only accessible to $20 \%$ of households in rural areas of the EU; $10 \%$ of rural households are not covered by any fixed networks [26, pp. 15, 20]. In general, DESI so far has been mainly focused on tracking the dynamics of inter-country imbalances; it does not specifically address the issue of reducing the digital divide between urban and rural areas. Experts from EPRI (European Platform for Rural Innovation - an independent virtual innovation centre for the development of rural innovations, smart

\footnotetext{
${ }^{14}$ Let us remember that the industry employs only $2 \%$ of the economically active population. Field work is performed mainly by seasonal migrants from North Africa and Eastern and SouthEastern Europe. For them, the regime of restrictions imposed by the pandemic had to be changed.
}

villages, bioeconomy and digitalization of management) $)^{15}$ point out the need to compile a separate DERSI (Digital Economy and Rural Society Index) index. They call for a deeper understanding of the differences between urban and rural economies in terms of such criteria as the availability of Internet services and e-commerce, the use of digital technologies in business and management, the spread of advanced skills for working with complex digital devices among rural residents.

Today, however, there is no firm evidence that rural areas of the European Union do not have a chance to succeed in the use of digital technologies. Urban areas are only $1 \%$ ahead of rural areas in terms of the share of young people, and there are only $1 \%$ more older people in them, which is not critical. Rural areas have a low level of people with higher education, but this level is growing. Finally, these areas receive the bulk of transfers from the EU Budget.

The CAP's Funds (annually they have more than 50 billion euros and they are the largest funds of the EU Budget) are combined with the system of administration and control. It protects the EU's financial resources from abuse, processing declarations on agricultural activities for the purpose of calculating direct payments to farmers and payments for rural development programs. The EC's "From Farm to Fork" strategy includes a plan to move from physical checks on farms to systematic automated checks on the compliance of farms with sustainable development targets.

The problems of the current stage arise from the lack of supranational regulation of ownership of agricultural data. It turns into a lack of objective data and miscalculations in the course of targeted support of farms. The solution consists in encouraging the wide use of the Internet of Things by means of CAP on the one hand and in rewarding farmers for transferring the competence to manage data obtained in their fields to the supranational level, on the other hand. In any case, since 2003 the provision of transfers and rewards to beneficiaries under the CAP has been dependent on the fulfillment of European standards, norms and quantitative benchmarks developed at the supranational level (this principle is called cross-compliance). Digitalization, in its turn, takes administrative procedures to a more advanced level.

The Next Generation EU recovery plan ${ }^{16}$ includes a wide range of financial incentives, one part of which is related to the traditional grant instruments of the EU Budget, and the other to the new extra-budgetary lending instruments. Access to them is based on the

\footnotetext{
${ }^{15}$ What does the 2020 Digital Economy and Society Index (DESI) report tell us about digital development in rural areas? Not enough. June 13, 2020. https://rural-innovation.eu/digital-economy-andsociety-index-rural-areas/. Cited November 10, 2020.

${ }^{16}$ For more details see: Europe's moment: Repair and Prepare for the Next Generation, COM(2020) 456 final; Council of the European Union. Special meeting of the European Council (July 17-21, 2020). Conclusions. Brussels, July 21, 2020.
} 
results of an objective monitoring of the contribution of farms to the tasks of building an environmentally friendly, inclusive and innovative/digital economy.

In order to encourage the hesitant member countries to move towards more ambitious investment activities, the EC tried to secure the agreement of their regional authorities and line ministries with its course; The Commission asked to declare one's intention to use its financial initiatives, it also offered expert services on adaptation and search for financial partners.

The EC already received consent to this. Thus, the Declaration "A Smart and Sustainable Digital Future for European Agriculture and Rural Areas" 17 signed in 2019 by EU countries (except Malta) specifically noted the importance of creating agri-food digital innovation centres (Agri-food digital innovation hubs) and systems of advanced training (Agricultural knowledge and innovation systems, AKISs) and the use of the European space programs EGNOS and Galileo and the Earth observation program Copernicus for the accurate and efficient operation of autonomous agricultural equipment. In May 2020, the EC accepted requests from 18 member states to provide services in the integration of green and digital economy objectives into their territorial programs and the establishment of a dialogue between the parties involved. ${ }^{18}$

Digitalization opens up new opportunities for a dialogue with external partners and an objective assessment of global problems. The EU's developments in digital green agriculture are highlighted in the FAO reports. The challenge for the future is to ensure that there is an ambitious chapter in all bilateral trade agreements. Sharing digital data will make it more productive for the partners to make commitments in the key areas such as high standards of livestock care, food safety, restricting the use of pesticides and antimicrobials, reducing food waste, and sustainable land use. The first achievements are proven, in particular, by the EU-Mercosur free trade agreement signed in June 2019.

\section{CONCLUSIONS}

Platform technologies, blockchain, Internet of things, artificial intelligence open a new page in the development of the EU agriculture. With their help it becomes possible to strengthen the unity of the internal market and facilitate the exchange of data; they provide an objective basis for the allocation of CAP transfers. Thus, the interest of the official EU in digital technologies stems from the possibility of their use as an unconventional acceleration tool in addition to the

\footnotetext{
${ }^{17}$ Declaration. A smart and sustainable digital future for European agriculture and rural areas. Brussels. April 5, 2019.

${ }^{18}$ EU budget for recovery: Questions and answers on the Just Transition Mechanism. European Commission. Brussels. May 28, 2020. https://ec.europa.eu/commission/presscorner/detail/en/qanda_20_931. Cited November 10, 2020.
}

existing political, legal and investment regulatory instruments.

Experience in the implementation of digital technologies has already been accumulated. EU institutions rely on a significant volume of practical knowledge about the opportunities and risks of digitalization. According to estimates the direct result-reduced production costs-will be limited due to the high cost of digital transformation. The main expected result is the possibility to solve such development goals as the rationalization of nature management, creation of closed-cycle farms, limitation of the volume of overproduction and expansion of activity in the European agricultural sector. These goals fall into the category of high-level or good goals that can justify supranational regulation of the digitalization of agriculture.

This justifies the costs of the EU Budget. CAP is ready for the implementation of the reform with the transfer of the next portion of responsibility to the supranational level and the inclusion of digitalization tasks in the existing mechanisms of financial conditionality of transfers. Direct payments to farmers and European investment programs targeted at rural areas are the incentives that will encourage agricultural actors to move in the direction of the EC strategy.

\section{REFERENCES}

1. O. Potemkina, "European Union: Seasonal workers under COVID-19 pandemic," Sci. Anal. Herald IE RAS, No. 5, 45-51 (2020). http://dx.doi.org/10.15211/vestnikieran520204551

2. Policy implications of Coronavirus crisis for rural development, 16 June, OECD 2020.

https://www.oecd.org/coronavirus/policy-responses/policy-implications-of-coronavirus-crisis-for-rural-development-6b9d189a/.

3. H. N. Gizatullin and V. A. Troitskii, "The concept of sustainable development: a new socioeconomic paradigm," Soc. Sci. Contemp. World, No. 5, 124-130 (1998).

4. Zh. A. Mingaleva, "Ideas for sustainable development: 'bone of contention' or platform for unification," Vestn. Mosk. Un-ta, Ser. 6: Ekonomika, No. 6, 23-41 (2017).

5. A. V. Kukushkina, "The concept of sustainable development (international legal aspects)," Vestn. Tomsk. Gos. Un-ta, Pravo, No. 23, 29-39 (2017).

6. B. N. Porfir'ev, “'Green' economy: Worldwide development trends and prospects," Herald Russ. Acad. Sci. 82 (2), 120-128 (2012).

7. B. Porfir'ev, "Green trends in the global financial system," Mir. Ekon. Mezhdunar. Otn. 60 (9), 5-16 (2016).

8. What is Digital Economy? Trends, Competences, Measurement, Ed. by L. M. Gokhberg (Izd. Dom Vysshej Shkoly Ekonomiki, Moscow, 2019) [in Russian].

9. R. A. Perelet, "Environmental aspects of the digital economy," Mir Nov. Ekon. 12 (4), 39-45 (2018). 
10. White paper: Digital technology and environment: Using the digital transition to accelerate the ecological transition (2018). https://www.iddri.org/sites/default/files/PDF/Publications/Catalogue\%20Iddri/Rapport /201804_white\%20paper\%20digital\%20ecology.pdf.

11. J. P. W. Scharlemann, R. C. Brock, N. Balfour, et al., "Towards understanding interactions between sustainable development goals: The role of environment-human linkages," Sustain. Sci. 15, 1573-1584 (2020).

12. L. Lebedeva, "Digital transformation in the sociolabor sphere: New challenges and opportunities," Mir. Ekon. Mezhdunar. Otn. 63 (12), 42-49 (2019).

13. L. Khudyakova, "Launching a sustainable financial system in the European Union," Mir. Ekon. Mezhdunar. Otn. 63 (7), 16-22 (2019).

14. V. N. Zuev, "Supranational mechanism in the system of global and regional regulation," Vestn. Mezhdunar. Org. 4 (30), 10-20 (2010).

15. N. Kaveshnikov, "Methods of governance in the European Union,” Mir. Ekon. Mezhdunar. Otn. 59 (8), 4960 (2015).

16. M. V. Strezhneva and I. L. Prokhorenko, Economic Governance in the European Union: Institutional and Political Issues (IMEMO RAN, Moscow, 2013) [in Russian].

17. S. Afontsev, "New trends in global economy," Mir. Ekon. Mezhdunar. Otn. 63 (5), 36-46 (2019). https://doi.org/10.20542/0131-2227-2019-63-5-36-46

18. T. Jackson, Prosperity without Growth? The Transition to a Sustainable Economy (Sustainable Development Commission, 2009). http://www.sd-commission.org.uk/data/files/publications/prosperity_without_growth_report.pdf. Cited November 10, 2020.
19. J. E. Stiglitz, "The economy we need," Project Syndicate (2019). https://www.project-syndicate.org/onpoint/the-economy-we-need-by-joseph-e-stiglitz2019-05?barrier=accesspaylog. Cited November 10, 2020.

20. Digital Technologies in Agriculture and Rural Areas (Food and Agriculture Organization of the United Nations, Rome, 2019).

21. Status of Digital Agriculture in 18 Countries of Europe and Central Asia (FAO, ITU, Geneva, 2020).

22. Modernising and Simplifying the CAP: Socio-Economic Challenges Facing EU Agriculture and Rural Areas (European Commission, Brussels, 2017).

23. K. Kosior, "Towards a new data economy for EU agriculture," Studia Europejskie-Studies in European Affairs 23 (4), 91-107 (2019). https://doi.org/1033067/SE.4.2019.6

24. A. Renda, Artificial Intelligence: Ethics, Governance and Policy Challenges: CEPS Task Force Report (CEPS, Brussels, 2019).

25. A. Renda, N. Reynolds, M. Laurer, and G. Cohen, Digitising Agrifood: Pathways and Challenges (CEPS, BCFN, Brussels, 2019).

26. Digital Economy and Society Index: Thematic Chapters (European Commission, Brussels, 2020).

27. V. N. Leksin, "Synthesis of consumer society and information society," Outlines Glob. Transformations: Politics, Economics, Law 13 (2), 195-211 (2020).

28. IoT and Digital Technologies for Monitoring of the New CAP (AIOTI WG06-Smart Farming and Food Security, 2019). 